\title{
Determinasi Sikap Profesi, Kompetensi Mengelola Proses Pembelajaran dan Kepemimpinan Kepala Sekolah terhadap Kepuasan Kerja Guru Sekolah Dasar
}

\author{
I M. Warga ${ }^{1}$, N. Dantes ${ }^{2}$, I N. Natajaya ${ }^{3}$ \\ ${ }^{123}$ Program Studi Pendidikan Dasar, Universitas Pendidikan Ganesha, Singaraja \\ e-mail: made.warga@pasca.undiksha.ac.id
}

\begin{abstract}
Abstrak
Penelitian ini bertujuan untuk mengetahui besarnya determinasi sikap profesi, kompetensi mengelola proses pembelajaran dan kepemimpinan kepala sekolah terhadap kepuasan kerja guru pada Sekolah Dasar di Kecamatan Melaya, Kabupaten Jembrana. Penelitian ini merupakan penelitian Expost Facto dan pengumpulan data yaitu menggunakan kuesioner. Penentuan responden berdasarkan table Krejeie dan Morgan yaitut sampel 148 guru yang diambil secara acak. Analisis data menggunakan regresi sederhana, korelasi parsial, regresi ganda, korelasi ganda. Hasil analisis data adalah sebagai berikut: Pertama: terdapat determinasi yang signifikan antara sikap profesi (X1) terhadap kepuasan kerja guru $(\mathrm{Y})$; Kedua: terdapat determinasi yang signifikan antara kompetensi mengelola proses pembelajaran $(\mathrm{X} 2)$ terhadap kepuasan kerja guru $(\mathrm{Y})$, Ketiga: terdapat determinasi yang signifikan antara kepemimpinan kepala sekolah (X3) terhadap kepuasan kerja guru (Y), dan Keempat: terdapat determinasi yang signifikan antara sikap profesi (X1), kompetensi mengelola proses pembelajaran (X2), kepemimpinan kepala sekolah (X3) terhadap kepuasan kerja guru (Y).
\end{abstract}

Kata Kunci: Sikap Profesi, Kompetensi Mengelola Proses Pembelajaran, Kepemimpinan, Kepuasan Kerja Guru

\begin{abstract}
This research aims at investigating the determination of profession attitude, teaching-learning process management competency, and principal's leadership on teachers' performance satisfaction of elementary school teachers in Melaya, Jembrana Regency. This was an expost-facto research which the data were gathered using questionnaire. The respondents were collected based on Krejeie and Morgan table and 148 teachers were taken randomly. The data were analyzed using simple regression, partial correlation, and multiple regressions. The results of the research are as follows. First, there is a significant determination between profession attitude (X1) on teachers' performance satisfaction $(\mathrm{Y})$. Second, there is a significant determination between teaching-learning process management competency $(\mathrm{X} 2)$ on on teachers' performance satisfaction $(\mathrm{Y})$. Third, there is a significant determination between principal's leadership (X3) on on teachers' performance satisfaction $(Y)$. Fourth, there is a significant determination among profession attitude (X1), teaching-learning process management competency (X2), principal's leadership (X3) on on teachers' performance satisfaction $(Y)$.
\end{abstract}

Keyword: profession attitude, teaching-learning process management competency, principal's leadership, teachers' performance satisfaction 


\section{Pendahuluan}

Salah satu faktor yang memegang peranan penting dalam pencapaian tujuan pendidikan adalah guru, karena guru bertindak sebagai fasilitator yang memungkinkan terciptanya kondisi kondusif bagi subjek didik. Guru merupakan profesi dengan tugas utama mendidik, mengajar, mengarahkan, melatih, menilai dan mengevaluasi kegiatan peserta didik dan selanjutnya membimbing peserta didik untuk dapat berkembang sesuai dengan bakat dan kemampuan yang dimiliki oleh masing-masing peserta diodik. Guna mendukung tugas secara professional, guru harus membekali diri dengan berbagai kompetensi teknis edukatif dan memiliki kepribadian serta kecakapan mengelola interaksi dengan sesama dan mengelola komunikasi yang interaktif dengan seluruh peserta didik.

Selain sikap terhadap profesi yang positif, pengelolaan proses pembelajaran perlu juga diperhatikan. Pembelajaran bukan kegiatan sepihak yang berlangsung dari guru kepada peserta didik, tetapi merupakan kegiatan interaktif antara guru dan peserta didik. Guru dengan segala pengalaman dan kewenangannya berusaha menyajikan materi dan kegiatan belajar yang menarik, bermanfaat dan bermakna. Selanjutnya peserta didik dengan didorong oleh rasa ingin tahu yang tinggi berusaha menggali pengalaman dan aktif mengikuti proses belajar yang berlangsung.

Kegiatan pembelajaran adalah kegiatan yang terencana dan dimaksudkan untuk memberi pengertian, pemahaman dan penguasaan atas pengetahuan yang telah disampaikan, kegiatan tersebut merupakan usaha bersama anatara guru dan peserta didik, pelaksanaan kegiatan pembelajaran dapat dilakukan di dalam kelas maupun di luar kelas. Kegiatan belajar bermakna (meaning full) adalah kegiatan belajar yang mampu kepada peserta didik, dan dengan pengetahuan awal tersebut, peserta didik tertarik untuk mencari dan meneliti berbagai masalah yang dianggapnya mampu memberi pengalaman dan pengetahuan bagi dirinya. Dalam konteks ini diperlukan guru dengan sikap yang positif terhadap profesinya dan kompetensi mengelola proses pembelajaran yang tinggi agar kehadirannya mampu memberikan nilai positif bagi proses belajar mengajar.

Kepemimpinan kepala sekolah tentu turut berperan serta membentuk lingkungan yang kondusif bagi guru dalam melaksanakan tugasnya. Guru menduduki posisi yang sangat setrategis yang akan memberikan kontribusi langsung terhadap kualitas hasil belajar peserta didik dan menjalankan semua program sekolah. Guna mencapai tujuan sekolah dibutuhkan etos kerja yang tinggi.Untuk menumbuhkan etos kerja yang tinggi pada guru dibutuhkan perhatian pada rasa kepuasan kerja guru.

Kepuasan kerja sangat penting dalam dunia pendidikan, proses pendidikan akan berjalan baik bila didukung oleh salah satu faktor yaitu kepuasan kerja. Kita dapat melihat, jika pada suatu sekolah terjadi ketidak puasan kerja akan mengakibatkan konflik intern di sekolah yang pada akhirnya menghambat kegiatan mengajar.Hal ini yang mendorong peneliti untuk melakukan penelitian tentang kepuasan kerja dengan tiga (3) variabel independen yaitu sikap profesi, kompetensi mengelola proses pembelajaran dan kepemimpinan kepala sekolah.

Penelitian ini rumusan masalahnya sebagai berikut; (1) Seberapa besar determinasi sikap profesi, terhadap kepuasan kerja guru sekolah dasar di Kecamatan Melaya, Kabupaten Jembrana, Bali ? (2)Seberapa besar determinasi kompetensi mengelola proses pembelajaran terhadap kepuasan kerja guru sekolah dasar di Kecamatan Melaya, Kabupaten Jembrana, Bali ? (3)Seberapa besar determinasi kepemimpinan kepala sekolah terhadap kepuasan kerja guru sekolah dasar di Kecamatan Melaya, Kabupaten Jembrana, Bali ? (4)Secara simultan, seberapa besar determinasi sikap profesi, kompetensi mengelola proses pembelajaran dan kepemimpinan kepala sekolah terhadap kepuasan kerja guru sekolah dasar di Kecamatan Melaya, Kabupaten Jembrana, Bali ?

Manfaat yang ingin dicapai melalui kegiatan penelitian ini adalah memberikan gambaran umum tentang tingkat kepuasan kerja guru sekolah dasar di Kecamatan Melaya, Kabupaten Jembrana, Bali.Secara lebih spesifik hasil penelitian ini diharapkan memiliki manfaat secara teoritis maupun praktis sebagai berikut. (1) Manfaat secara teoretis: (a) Sebagai bahan kajian kepada sekolah untuk digunakan dalam menyusun rencana dan setrategi (renstra ) dalam rangka meningkatkan kualitas kepuasan kerja guru. (b) Sebagai 
bahan masukan kepada sekolah tentang sikap profesi, kompetensimengelola proses pembelajaran dan kepemimpinan kepala sekolah yang berpengaruh terhadap kepuasan kerja guru sekolah dasar, di Kecamatan Malaya, Kabupaten Jembrana, Bali. (c) Hasil penelitian ini dapat digunakan oleh kepala sekolah dalam mengelola institusi pendidikan agar lebih kondusif dan lebih mampu mewujudkan kepuasan kerja guru, serta memiliki strategi yang tepat dalam menciptakan sikap profesi yang positif dan meningkatkan kompetensi mengelola proses pembelajaran sehingga tujuan sekolah yang dipimpinnya tercapai. (2) Manfaat secara praktis: (a) Secara langsung dapat diketahui kelebihan dan kekurangan guru terhadap sikap profesi dan kompetensi mengelola proses pembelajaran yang dimiliki oleh guru sekolah dasar dikecamatan Melaya, Kabupaten Jembrana, Bali melalui hasil koesioner yang diedarkan (b) Secara langsung dapat diketahui sejauh mana kepemimpinan kepala sekolah berpengaruh terhadap kepuasan kerja guru sekolah dasar di Kecamatan Melaya, Kabupaten Jembrana, Bali melalui hasil koesioner yang diedarkan.(c) Secara langsung bagi kepala sekolah sebagai bahan kajian dalam kepemimpinannya untuk berbenah diri terhadap kekurangan - kekurangan yang diperoleh dari hasil koesioner diedarkan.

\section{Metode}

Penelitian ini menggunakan desain expost facto, karena dengan menggunakan teknik korelasional, dan tidak mengadakan manipulasi terhadap gejala yang diteliti dan gejala yang diteliti merupakan gejala yang sudah ada di lapangan. Variabel yang akan diteliti adalah 4 (empat) variable, yaitu : (1) sikap profesi, (2) kompetensi mengelola proses pemblajaran, (3) kepemimpinan kepala sekolah sebagai variabel bebas, serta (4) kepuasan kerja guru sebagai variabel terikat.Adapun jumlah populasi guru Sekolah Dasar Negeri yang didapat dari data resmi Unit Pelaksana Teknis( UPT.) Dikporaparbud.Kecamatan Melaya adalah sebanyak 238 orang yaitu yang tersebar pada 35 sekolah negeri dan 2 sekolah swasta. Berdasarkan tabel krejeie dan Morganmaka dari jumlah populasi 238 guru sekolah dasar negeri diperoleh sampel sebanyak 148 guru, yaitu 238 dibulatkan menjadi 240 dan 240 ini sesuai dengan table diatas terdapatlah sampel 148 guru yang nantinya diambil secara acak.

Instrumen penelitian sikap profesi guru, kepemimpinan kepala sekolah dan kepuasan kerja guru disusun dalam bentuk kuesioner pola Likert.

\section{Hasil dan Pembahasan}

\section{Deskripsi Data Hasil Penelitian}

Tabel 3.1. Rangkuman Statistik Masing-masing Variabel

\begin{tabular}{|c|c|c|c|c|}
\hline $\begin{array}{l}\text { Variabel } \\
\text { Statistik }\end{array}$ & $X_{1}$ & $X_{2}$ & $\mathbf{X}_{3}$ & $\mathbf{Y}$ \\
\hline Rata-rata & 120,68 & 80,36 & 127,59 & 160,70 \\
\hline Nilai Tengah & 119 & 80,00 & 126,50 & 159,50 \\
\hline Modus & 114 & 80 & $117^{\mathrm{a}}$ & 158 \\
\hline Simpangan Baku & 13,202 & 6,375 & 13,908 & 13,093 \\
\hline Varian & 174,286 & 40,640 & 193,428 & 171,421 \\
\hline Rentangan & 58 & 29 & 60 & 59 \\
\hline Skor Minimum & 97 & 64 & 97 & 133 \\
\hline Skor Maksimum & 155 & 93 & 157 & 192 \\
\hline Jumlah & 17861 & 11893 & 18883 & 23784 \\
\hline
\end{tabular}

(Perhitungan dapat dilihat pada lampiaran 3.a) 


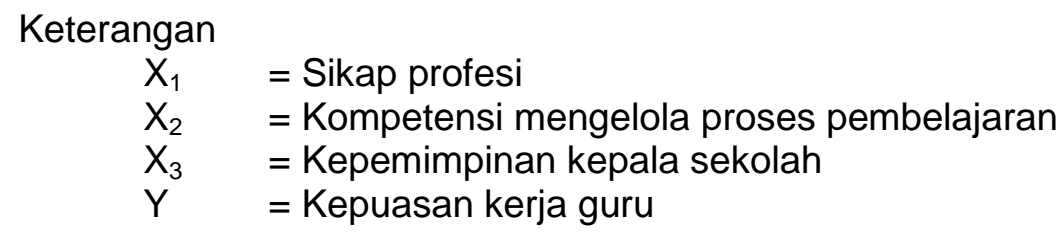

\section{Determinasi antara Sikap profesi $\left(\mathrm{X}_{1}\right)$ dengan Kepuasan kerja guru (Y) di Sekolah Dasar Di Kecamatan Melaya Kabupaten Jembrana}

Berdasarkan atas uji hipotesis terdapat determinasi yang positif dan signifikan antara sikap profesi dengan kepuasan kerja guru. Hasil perhitungan regresi sederhana $Y$ atas $X_{1}$ ditemukan persamaan $Y=94,375+0,55$ X1dengan $F_{\text {hitung }}=64,714$ dengan $F_{\text {tabel }}=4,00$ $\left(F_{\text {hitung }}>F_{\text {tabel }}\right)$ adalah signifikan dan linier. Kuat hubungan antara sikap profesi $\left(X_{1}\right)$ dengan kepuasan kerja guru (Y) di Sekolah Dasar Di Kecamatan Melaya Kabupaten Jembrana dihitung dengan determinasi product moment, berdasarkan analisis diperoleh besarnya $r$ hitung $=0,554$ lebih besar dari $r$ tabel $=0,159$ pada $\alpha=0,05$ adalah signifikan, dengan determinasi $\left(r^{2}=0,307\right)$.

Berdasarkan hasil analisis tersebut dapat disimpulkan bahwa terdapat determinasi yang positif dan signifikan antara sikap profesi $\left(\mathrm{X}_{1}\right)$ dengan kepuasan kerja guru $(\mathrm{Y}) \mathrm{di}$ Sekolah Dasar di Kecamatan Melaya Kabupaten Jembrana dengan determinasi sebesar $41,11 \%$. Dengan kata lain dapat dinyatakan bahwa makin baik tingkat sikap profesi , maka makin tinggi pula tingkat kepuasan kerja guru Sekolah Dasar Di Kecamatan Melaya Kabupaten Jembrana, sedangkan sisanya lagi 58,89\% merupakan determinasi faktor lain yang tidak diteliti.

Determinasi sikap profesi ada sebesar $41,11 \%$ mengidentifikasikan bahwa sikap profesi dapat dipakai sebagai prediktor kepuasan kerja guru Sekolah Dasar Di Kecamatan Melaya Kabupaten Jembrana. Sumbangan efektif sikap profesi sebesar 20,57\% mengidikasikan bahwa efektivitas sikap profesi cukup optimal dalam mempengaruhi kepuasan kerja guru. Dengan kata lain dapat dikatakan bahwa kepuasan kerja guru yang baik di Sekolah Dasar Di Kecamatan Melaya Kabupaten Jembrana lebih banyak dipengaruhi oleh gaya sikap profesi dibandingkan dengan kompetensi mengelola proses pembelajaran dan kepemimpinan kepala sekolah guru.

\section{Determinasi antara Kompetensi mengelola proses pembelajaran (X2) dengan Kepuasan kerja guru (Y) di Sekolah Dasar Di Kecamatan Melaya Kabupaten Jembrana.}

Berdasarkan atas uji hipotesis terdapat determinasi yang positif dan signifikan antara kompetensi mengelola proses pembelajaran dengan kepuasan kerja guru. Hasil perhitungan regresi sederhana $Y$ atas $X_{2}$ ditemukan persamaan $Y=62,942+1,217$ X2dengan $F_{\text {hitung }}=$ 78,918 dengan $F_{\text {tabel }}=4,00\left(F_{\text {hitung }}>F_{\text {tabel }}\right)$ adalah signifikan dan linier. Kuat hubungan antara kompetensi mengelola proses pembelajaran (X2) dengan kepuasan kerja guru (Y) di Sekolah Dasar Di Kecamatan Melaya Kabupaten Jembrana dihitung dengan determinasi product moment, berdasarkan analisis diperoleh besarnya $r$ hitung $=0,592$ lebih besar dari $r$ tabel $=0,159$ pada $\alpha=0,05$ adalah signifikan, dengan determinasi $\left(r^{2}=0,351\right)$.

Berdasarkan hasil analisis tersebut dapat disimpulkan bahwa terdapat determinasi yang positif dan signifikan antara kompetensi mengelola proses pembelajaran (X2) dengan kepuasan kerja guru (Y) di Sekolah Dasar Di Kecamatan Melaya Kabupaten Jembrana dengan determinasi sebesar $35,1 \%$. Dengan kata lain dapat dinyatakan bahwa makin baik kompetensi mengelola proses pembelajaran guru yang ada di sekolah, maka makin tinggi pula tingkat kepuasan kerja guru Sekolah Dasar Di Kecamatan Melaya Kabupaten Jembrana, sedangkan sisanya lagi 53,4\% merupakan determinasi faktor lain yang tidak diteliti.Sumbangan efektif kepemimpinan kepala sekolah sekolah sebesar 16,67\% mengidikasikan bahwa efektivitas kompetensi mengelola proses pembelajaran cukup optimal dalam mempengaruhi kepuasan kerja guru. 
Dengan kata lain dapat dikatakan bahwa kepuasan kerja guru yang baik di Sekolah Dasar di Kecamatan Melaya Kabupaten Jembrana lebih banyak dipengaruhi oleh kompetensi mengelola proses pembelajaran selain sikap profesi dan kepemimpinan kepala sekolah sekolah. Dengan demikian dapat disimpulkan bahwa hipotesis nol $\left(\mathrm{H}_{0}\right)$ yang menyatakan 'tidak terdapat determinasi yang positif dan signifikan antara kompetensi mengelola proses pembelajaran dengan kepuasan kerja guru Sekolah Dasar di Kecamatan Melaya Kabupaten Jembrana' ditolak. Sedangkan hipotesis alternatif $\left(\mathrm{H}_{1}\right)$ yang menyatakan "terdapat determinasi yang positif dan signifikan antara kompetensi mengelola proses pembelajaran dengan kepuasan kerja guru Sekolah Dasar di Kecamatan Melaya Kabupaten Jembrana" diterima.

\section{Determinasi antara Kepemimpinan kepala sekolah Sekolah $\left(X_{3}\right)$ dengan Kepuasan kerja guru (Y) di Sekolah Dasar Di Kecamatan Melaya Kabupaten Jembrana}

Berdasarkan atas uji hipotesis terdapat determinasi yang positif dan signifikan antara kepemimpinan kepala sekolah sekolah dengan kepuasan kerja guru. Hasil perhitungan regresi sederhana $Y$ atas $X_{3}$ ditemukan persamaan $Y=96,985+0,499$ X3dengan $F_{\text {hitung }}=$ 57,178 dengan $F_{\text {tabel }}=4,00\left(F_{\text {hitung }}>F_{\text {tabel }}\right)$ adalah signifikan dan linier. Kuat hubungan antara kepemimpinan kepala sekolah sekolah $\left(\mathrm{X}_{3}\right)$ dengan kepuasan kerja guru $(\mathrm{Y})$ di Sekolah Dasar Di Kecamatan Melaya Kabupaten Jembrana dihitung dengan determinasi product moment, berdasarkan analisis diperoleh besarnya $r$ hitung $=0,618$ lebih besar dari $r$ tabel $=$ 0,159 pada $\alpha=0,05$ adalah signifikan, dengan determinasi $\left(r^{2}=0,351\right)$.

Determinasi kepemimpinan kepala sekolah sekolah ada sebesar $28,1 \%$. mengindikasikan bahwa kepemimpinan kepala sekolah sekolah dapat dipakai sebagai prediktor kepuasan kerja guru Sekolah Dasar Di Kecamatan Melaya Kabupaten Jembrana. Sumbangan efektif kepemimpinan kepala sekolah sekolah sebesar 18,54\% mengidikasikan bahwa efektivitas kepemimpinan kepala sekolah sekolah cukup optimal dalam mempengaruhi kepuasan kerja guru. Dengan kata lain dapat dikatakan bahwa kepuasan kerja guru yang baik di Sekolah Dasar Di Kecamatan Melaya Kabupaten Jembrana lebih banyak dipengaruhi oleh kepemimpinan kepala sekolah sekolah selain sikap profesi kompetensi mengelola proses pembelajaran guru. Dengan demikian dapat disimpulkan bahwa hipotesis nol $\left(\mathrm{H}_{0}\right)$ yang menyatakan "tidak terdapat determinasi yang positif dan signifikan antara kepemimpinan kepala sekolah sekolah dengan kepuasan kerja guru Sekolah Dasar Di Kecamatan Melaya Kabupaten Jembrana".Sedangkan hipotesis alternatif $\left(\mathrm{H}_{1}\right)$ yang menyatakan "terdapat determinasi yang positif dan signifikan antara kepemimpinan kepala sekolah sekolah dengan kepuasan kerja guru Sekolah Dasar Di Kecamatan Melaya Kabupaten Jembrana" diterima.

\section{Determinasi Secara Bersama-sama Sikap profesi $\left(X_{1}\right)$, Kompetensi mengelola proses pembelajaran (X2) dan Kepemimpinan kepala sekolah Sekolah $\left(X_{3}\right)$ terhadap Kepuasan kerja guru (Y) di Sekolah Dasar Di Kecamatan Melaya Kabupaten Jembrana.}

Hasil perhitungan regresi sederhana $Y$ atas $X_{1}, X_{2}, X_{3}$ ditemukan persamaan regresi $Y=0,368 X 1+0,578 X 2+0,329 X 3+27,836$ dengan $F_{\text {hitung }}=60,562>F_{\text {tabel }}(\alpha=0,05)=$ 4,00 ( $\left.F_{\text {hitung }}>F_{\text {tabel }}\right)$ adalah signifikan dan linier. Kuat hubungan antara Sikap profesi $\left(X_{1}\right)$, kompetensi mengelola proses pembelajaran (X2) dan kepemimpinan kepala sekolah sekolah $\left(\mathrm{X}_{3}\right)$ dengan kepuasan kerja guru $(\mathrm{Y})$ di Sekolah Dasar Di Kecamatan Melaya Kabupaten Jembrana dihitung dengan determinasi product moment, berdasarkan analisis diperoleh besarnya $r$ hitung $=0,747$ lebih besar dari $r$ tabel $=0,159$ pada $\alpha=0,05$ adalah signifikan, dengan determinasi $\left(r^{2}=0,558\right)$.

Berdasarkan hasil analisis tersebut dapat disimpulkan bahwa terdapat determinasi yang positif dan signifikan antara Sikap profesi $\left(X_{1}\right)$, kompetensi mengelola proses pembelajaran (X2) kepemimpinan kepala sekolah sekolah $\left(X_{3}\right)$ dengan kepuasan kerja guru (Y) di Sekolah Dasar Di Kecamatan Melaya Kabupaten Jembrana dengan determinasi sebesar 55,8 \% Sedangkan sisanya lagi 32\% merupakan determinasi faktor lain yang tidak 
diteliti. Dengan demikian dapat disimpulkan bahwa hipotesis nol $\left(\mathrm{H}_{0}\right)$ yang menyatakan "tidak terdapat determinasi yang positif dan signifikan antara Sikap profesi , kompetensi mengelola proses pembelajaran, kepemimpinan kepala sekolah sekolah dengan kepuasan kerja guru (Y) ) di Sekolah Dasar Di Kecamatan Melaya Kabupaten Jembrana" ditolak. Sedangkan hipotesis alternatif $\left(\mathrm{H}_{1}\right)$ yang menyatakan "terdapat determinasi yang positif dan signifikan antara Sikap profesi , kompetensi mengelola proses pembelajaran, kepemimpinan kepala sekolah sekolah dengan kepuasan kerja guru (Y) ) di Sekolah Dasar di Kecamatan Melaya Kabupaten Jembrana" diterima Selaras dengan penelitian Ardiatmika Adnyana, I Ketut (2011) dengan judul Determinasi Kepemimpinan Kepala Sekolah, Pelaksanaan Supervisi Akademik dan Sikap guru terhadap profesinya dengan kinerja guru matematika diSMP Negeri di Kabupaten Jembrana. Hasil temuan penelitian adalah terdapat determinasi yang signifikan sikap guru terhadap profesinya dengan kinerja guru matematika diSMP Negeri di Kabupaten Jembrana baik secara bersama-sama maupun sendiri.

Yanti Widiastuti (2010) melakukan penelitian terhadap kepemimpinan situasional, motivasi kerja dan iklim kerja terhadap kinerja guru pada SMA Negeri 2 Mengwi.Berdasarkan hasil analisis data diperoleh temuan adanya korelasi yang signifikan antara iklim kerja guru terhadap kinerja guru baik secara bersama-sama maupun terpisah.

Berbeda dengan Rahman (2012) melakukan penelitian dengan Judul Kontribusi Iklim Organisasi, Komitmen Guru dan Kepuasan Kerja Terhadap Prestasi Kerja SMAN 1 Mendoyo dikabupaten Jembrana.Hasil temuannya adalah adanya korelasi yang signifikan antara komitmen guru terhadap prestasi kerja guru baik secara simultan maupun terpisah

\section{Simpulan dan Saran}

Berdasarkan hasil penelitian disimpulkan dari temuan mengenai determinasi antara sikap profesi (X1), kompetensi mengelola proses pembelajaran (X2), dan kepemimpinan kepala sekolah (X3), terhadap kepuasan kerja guru (Y) di Sekolah Dasar di Kecamatan Melaya Kabupaten Jembrana, yaitu sebagai berikut: (1) Terdapat determinasi yang positif dan signifikan antara sikap profesi dengan kepuasan kerja guru di Sekolah Dasar Di Kecamatan Melaya Kabupaten Jembrana dengan determinasi sebesar 30,7\% dan sisanya lagi 69,30\% merupakan determinasi faktor lain yang tidak diteliti (2) Terdapat determinasi yang positif dan signifikan antara kompetensi mengelola proses pembelajaran dengan kepuasan kerja guru di Sekolah Dasar Di Kecamatan Melaya Kabupaten Jembrana dengan determinasi debesar 35,1 \% dan sisanya lagi 64,9\% merupakan determinasi faktor lain yang tidak diteliti (3) Terdapat determinasi yang positif dan signifikan antara kepemimpinan kepala sekolah sekolah dengan kepuasan kerja guru di Sekolah Dasar Di Kecamatan Melaya Kabupaten Jembrana dengan determinasi sebesar $28,1 \%$ dan sisanya lagi $71,9 \%$ merupakan determinasi faktor lain yang tidak diteliti. (4) Terdapat determinasi yang positif dan signifikan secara bersama-sama antara sikap profesi, kompetensi mengelola proses pembelajaran dan kepemimpinan kepala sekolah dengan kepuasan kerja guru di Sekolah Dasar Di Kecamatan Melaya Kabupaten Jembrana dengan determinasi sebesar 55,8 \% dan sisanya lagi $44,2 \%$ merupakan determinasi faktor lain yang tidak diteliti.

Berdasarkan temuan dalam penelitian ini menunjukkan bahwa variabel penelitian tentang sikap profesi, kompetensi mengelola proses pembelajaran, kepemimpinan kepala sekolah terdapat determinasi yang positif dan signifikan terhadap kepuasan kerja guru Sekolah Dasar Di Kecamatan Melaya Kabupaten Jembrana. Berdasarkan temuan dalam penelitian ini, dapat disarankan beberapa hal sebagai berikut: (a) Bagi Kepala Sekolah Hendaknya bekerja sesuai dengan aturan sikap profesi yang benar dalam arti pendelegasian dan pendistribusian tugas secara merata serta berusaha untuk selalu bersikap adil kepada guru dan staff pegawai, serta diharapkan bersifat fleksibel dan terbuka. Keterbukaan akan menjadi inspirasi positif bagi guru, tentunya melibatkan guru dalam setiap pengambilan keputusan. (2) Bagi Guru; Bekerjalah dengan profesional. Dengan kompetensi mengelola proses pembelajaran yang tinggi guru bisa mencapai jenjang karir dengan prestasi-prestasi edukatif. (3) Bagi Pengambil Kebijakan khususnya Dinas Pendidikan, dalam pengangkatan 
agar selalu memperhatikan kemampuan sikap profesi . (4) Bagi peneliti yang lain diharapkan untuk dapat mengembangkan hasil penelitian ini, yang belum diungkap didalam pembahasan ini, baik melalui peneltian kuantitatif maupun kualitatif.

\section{Daftar Pustaka}

Ardiatmika Adnyana, I Ketut. 2011. kepemimpinan kepala sekolah, supervisi akademik dan sikap guru terhadap profesinya dengan kinerja guru matematika SMP Negeri di Kabupaten Jembrana.Jurnal Ilmiah Pendidikan dan Pembelajaran. Program Pascasarjana Universitas Pendidikan Ganesha Singaraja. Vol 7 No. 2 Tahun 2011.

Anwar, Qomary dan Syaiful Sagala.2004. Profesi Jabatan Kependidikan dan Guru Sebagai Upaya Menjamin Kualitas Pembelajaran.Jakarta : Uhamka Press

Anwar, M. Idochi. 2004. Administrasi Pendidikan dan Manajemen Biaya Pendidikan. Bandung: Alfabeta

Atmodiwiro S. 2005. Manajemen Pendidikan Indonesia. Jakarta: Ardadizya Jaya.

Azwar, Saifuddin. 1988. Sikap Manusia: Teori dan Pengukurannya. Yogyakarta: Liberty.

Bafadal. 2009. Pengelolaan Perspustakaan Sekolah. Jakarta: Bumi Aksara.

Damayanti, Ni Nyoman. 2009. Study Korelasi antara Motivasi Berprestasi, Kompetensi Profesional dan Iklim Kerja Sekolah terhadap Kinerja Guru SMP Cahaya Harapan Indonesia Sejahtra (CHIS) Denpasar. Singaraja: Tesis Program Pascasarjana, Undhiksa.

Mulyasa.2007. Standar Kompetensi dan Sertifikasi Guru. Bandung: Rosda Karya

--------. 2007. Menjadi Guru Profesional. Bandung: Rosda Karya

Makmun, H. A. S. 2004. Psikologi Kependidikan. Bandung. Rosda Karya

Naditayasa, I Wayan. 2009. Determinasi Sikap Guru Terhadap Profesinya, Konsep Diri Guru dan Iklim Kerja Sekolah terhadap Kinerja Guru Olahraga SMP Negeri di Kabupaten Tabanan. Singaraja: Tesis Pasacasarjana Undiksha.

Ridwan. 2005. Belajar Mudah Penelitian Untuk Guru, Karyawan dan Peneliti Pemula. Bandung: Alfabeta

Ridwan dan Engkos Achmad Kuncoro.2006. Cara Menggunakan dan Memakai Analisis Jalur (Path Analisis). Bandung: Alfabeta

Santosa, Murwani. 2005. Model Proposial. Bahan Kuliah Statistika. Jakarta: Pasca Uhamka

Setiaji, Bambang. 2004. Panduan Riset dengan Pendekatan Kuantitatif. Surakarta: Program Pascasarjana UMS.

Suharsismi, Arikunto. 2004. Managemen Penelitian. Jakarta: Rineka Cipta

Sujoko, Harianto Adi. 2003. Pengaruh Kepemimpinan Kepala Sekolah dan Lingkungan Kerja terhadap Kinerja Guru SMU Negeri 3 Sukoharjo. Surakarta: Tesis Pascasarjana UMS.

Sunarni, Nani. 2006. Pengaruh Kepemimpinan Kepala Sekolah terhadap Kepuasan Kerja Guru SMA Negeri di Kabupaten Kuningan.Tesis. Bandung: Program Pascasarjana, Universitas Pendidikan Indonesia. 
Sutama. 2006. Hubungan Motivasi Berprestasi, Lingkungan Kerja, Kepuasan Kerja terhadap Prestasi Kerja Dosen Politeknik Negeri Bali. Singaraja: Tesis Pascasarjana Undiksha.

Suyastra. 2008. Hubungan antara Kompetensi, Sikap Profesional dan Motivasi Berprestasi terhadap Kinerja Guru pada SMA Negeri Unggulan di Denpasar. Singaraja: Tesis Pascasarjana Undiksha.

Syah, Muhibin. 2003, Dasar-dasar Psikologi Pendidikan dengan Pendekatan Baru, Bandung: Remaja Rosda Karya

Tilaar, H. A.R.. 2005. Manifesto Pendidikan Nasional. Tinjauan dari perspektif postmodernisme dan studi kultural. Jakarta: Penerbit Buku Kompas

Undang-Undang Republik Indonesia Nomor 14 Tahun 2005. Jakarta: Karya Mandiri 